\title{
Elasticidade, plasticidade, histerese... e ondas
}

(Elasticity, plasticity, hysteresis... and waves)

\author{
Luiz André Mützenberg묘, Eliane Angela Veit ${ }^{2}$ e Fernando Lang da Silveira ${ }^{2}$ \\ ${ }^{1}$ FETLSVC, Fundação Liberato, Novo Hamburgo, RS, Brasil \\ ${ }^{2}$ Instituto de Física, Universidade Federal do Rio Grande do Sul, RS, Brasil \\ Recebido em 20/10/2004; Aceito em 06/12/2004
}

\begin{abstract}
Neste artigo é descrito um experimento que permite estudar as propriedades mecânicas de fios sob tração. O experimento requer um monocórdio, no qual o fio é esticado e tangido, um microcomputador com placa de som e um software para análise espectral do som emitido pelo fio. São apresentados resultados experimentais para fios de cobre e aço que ilustram a determinação do módulo de Young, os regimes de deformação elástica não-lineares, os regimes de deformação plástica e as curvas de histerese para os fios. $\mathrm{O}$ experimento permite detectar também efeitos de dispersão nas ondas transversais que se propagam nos fios.

Palavras-chave: elasticidade, plasticidade, histerese, resistência de materiais, dispersão de ondas mecânicas.
\end{abstract}

We describe an experiment that enables to study mechanical properties of wires. The experiment requires a monostring to stretch the wire, a microcomputer with sound card, and a software to analyze the sound produced by the wire when it is tolled. Experimental data are shown for copper and steel wires that illustrate the determination of Young modulus, the regimes of nonlinear elastic deformation and of plastic deformation, and hysteresis curves. The experiment also enables to detect dispersion effects on transversal waves which propagate on the wires.

Keywords: elasticity, plasticity, hysteresis, stress diagrams, mechanical wave dispersion.

\section{Introdução}

Na derradeira obra de Galileu (1638), Discurso e Demonstrações Matemáticas sobre Duas Novas Ciências, o cientista italiano apresentou suas teorias sobre a resistência dos materiais e sobre os movimentos. Atualmente em disciplinas de Física Geral a resistência dos materiais é pouco estudada, restringindo-se ao domínio das pequenas deformações elásticas, onde vigem relações lineares entre tensão e deformação. As atividades experimentais atinentes a tais conteúdos, quando existentes, dificilmente ultrapassam o estudo de sistemas elásticos que obedecem à lei de Hooke.

Neste trabalho descrevemos um procedimento para estudar as características elásticas e plásticas de fios de aço e cobre, a partir da determinação das freqüências de oscilação dos mesmos em um monocórdio, uti- lizando um computador e materiais comuns em pequenas oficinas. Apresentamos os resultados experimentais, onde se determinam o módulo de Young, os regimes de deformação elástica não-lineares, os regimes de deformação plástica e as curvas de histerese para os fios. O experimento permite detectar também efeitos de dispersão nas ondas transversais que se propagam nos fios.

\section{Embasamento teórico}

No estudo de propriedades mecânicas dos materiais, são importantes as deformações provocadas por compressão, cisalhamento e tração [1,2]. Aqui nos limitamos à tração, pois pretendemos investigar o comportamento das deformações de fios em função da tensão aplicada.

\footnotetext{
${ }^{1}$ Enviar correspondência para Fernando Lang da Silveira. E-mail: lang@ufrgs.br.
} 
Um fio submetido a uma força $F$, sofre uma tensão de tração dada por:

$$
T=\frac{F}{A},
$$

onde $A$ é a área da secção reta do fio, e uma deformação, $D$, definida como:

$$
D=\frac{L-L_{0}}{L_{0}}
$$

onde $L_{0}$ é comprimento inicial e $L$ é o comprimento final do fio.

Para pequenas deformações $\left(D<10^{-3}\right), T$ pode ser considerado proporcional a $D$, em uma boa aproximaçãd2, e a deformação é reversível, ou seja, o fio retorna ao seu comprimento original quando cessa a tensão. À medida que $T$ cresce, a relação entre $T$ e $D$ deixa de ser linear, mas ainda assim a deformação é reversivel, ou elástica, até um determinado valor da tensão aplicada. Quando o limite elástico é ultrapassado, o fio perde a capacidade de retornar ao seu comprimento original, e diz-se que apresenta comportamento plástico. Para tensões ainda maiores o fio pode não suportar mais a tração, rompendo-se para um determinado valor mínimo de tensão, chamado de tensão de ruptura.

Dentro da região de elasticidade, define-se o módulo de Young, ou módulo de elasticidade, como a razão entre $T$ e $D$. Logo, para pequenas deformações em fios metálicos, o módulo de Young é constante.

Mesmo que o material seja elástico, são freqüentes as situações em que as curvas de deformação e de relaxamento não coincidem. Este fenômeno é conhecido como histerese elástica e resulta da dissipação de energia elástica, cujo valor por unidade de volume pode ser determinado da área entre as curvas de tensão em função da deformação. Alguns materiais, expostos a tensões contínuas, alteram suas propriedades elásticas de tal modo que a variação da tensão no fio com a deformação varia com o tempo. Dados experimentais destes fenômenos são apresentados na seção 4.

O procedimento adotado para estudar a relação entre $T$ e $D$ consiste em gravar o som emitido pelo fio esticado e posteriormente analisar seu espectro sonoro, para determinar as frequiências das ondas estacionárias, $f_{n}$, que se estabelecem no fio. Como o fio, de comprimento $L$, está preso nas duas extremidades, só pode oscilar nos seus modos normais de vibração, com um nodo em cada extremidade. Assim, pode-se calcular a velocidade, $v$, com que as ondas transversais se propagam no fio, através da relação:

$$
v=\frac{2 L}{n} f_{n}, \quad n=1,2,3, \ldots
$$

Obtém-se, então, a força tensora, $F$, lembrando que a velocidade de propagação de uma onda transversal em um fio depende desta força e da densidade linear de massa do fio, $\mu \mathrm{g}$ do seguinte modo:

$$
v=\sqrt{\frac{F}{\mu}} .
$$

A densidade linear do fio pode ser determinada medindo o comprimento do fio e a sua massa (em uma balança de precisão) ou a partir do diâmetro (volume) do fio e da densidade do material.

Os gráficos de Tensão $\times$ Deformação, apresentados na seção 4, permitem identificar a região elástica e a região plástica, bem como o limite de proporcionalidade e o limite de elasticidade, mas mais importante que estes aspectos de visualização direta, é a interpretação destes gráficos. No intervalo de vigência das relações lineares entre $T$ e $D$, a declividade da curva corresponde ao módulo de elasticidade do material. A área sob a curva representa a energia por unidade de volume envolvida nos diferentes processos de deformação do material.

\section{Montagem experimental e procedi- mentos de medida}

O monocórdio, esquematizado na Fig. 1, consiste de uma caixa de $75 \mathrm{~cm} \times 15 \mathrm{~cm} \times 10 \mathrm{~cm}$ confeccionada em madeira, com blocos maciços nas extremidades para viabilizar uma boa fixação dos eixos usados para esticar o fio. A distância entre os cutelos, $L_{0}$, é $66 \mathrm{~cm}$ e o diâmetro dos eixos, nos quais é enrolado o fio, é de $7,0 \mathrm{~mm}$. Esta medida é importante pois a determinação da variação do comprimento do fio, $\Delta L$, é função do ângulo de giro do eixo. Conhecendo a variação de comprimento do fio e seu comprimento inicial, $L_{0}$, calcula-se a deformação do fio (Eq. 2).

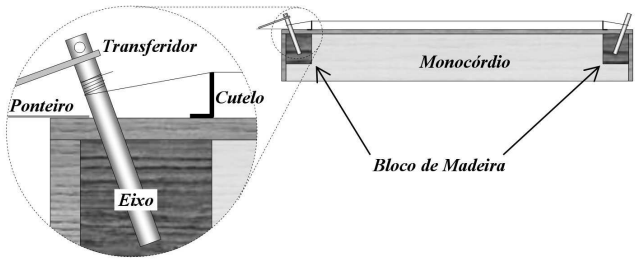

Figura 1 - Esquema de construção do monocórdio utilizado para esticar os fios.

\footnotetext{
${ }^{2}$ Discutiremos esta aproximação na seção 4 .
} 
Para a determinação da força tensora no fio utilizase um software. Optamos pelo Spectrogram [3], que efetua a transformada rápida de Fourier (FFT - Fast Fourier Transform), permitindo que se determine as freqüências presentes no som previamente gravado. A Fig. 2a, gerada pelo Spectrogram, mostra um gráfico da freqüência em função do tempo. A escala de cinzas representa a intensidade relativa de cada freqüência. Este gráfico permite identificar as freqüências do ruído de fundo, reveladas por linhas horizontais contínuas. As freqüências emitidas pelo fio somente ocorrem nos instantes em que é tangido. "Clicando" em qualquer ponto do gráfico, o software gera um gráfico da intensidade relativa em função da freqüência para este instante (Fig. 2b). A partir dos espectros instantâneos, determinam-se as freqüências emitidas pelo fio nos diferentes momentos em que foi tangido e, conforme descrito na seção 2 , a força tensora no fio.

a)

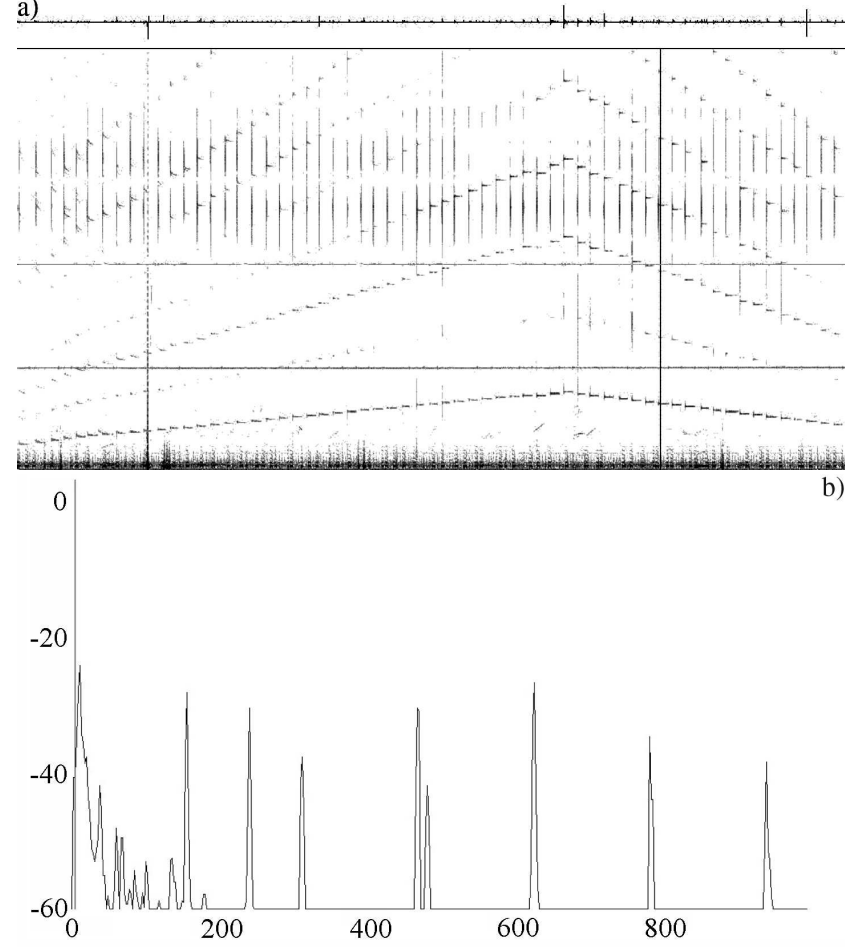

Figura 2 - (a) Gráfico típico da frequiência em função do tempo, gerado pelo Spectrogram $(\mathrm{R}$. (b) Exemplo de espectro sonoro emitido por um fio de aço.

A resolução de freqüências do espectro sonoro é limitada pelo número de pontos usados na transformada de Fourier e, neste software, não é melhor que um hertz. Se a velocidade da onda é independente da ordem do harmônico, pode-se determinar com maior precisão a força tensora no fio a partir de harmônicos de ordem superior, pois com um harmônico de ordem $n$, obtêm-se uma resolução $n$ vezes maior para a freqüência. Na prática, entretanto, um modelo em que a velocidade de propagação de ondas transversais independe da freqüência deixa de ser bom a freqüências maiores, como pode ser visto nos resultados da seção 4 .

\section{Resultados experimentais}

Como exemplo de material com comportamento elástico foi escolhido um fio de aço, especial para molas, e como exemplo de material com comportamento plástico optou-se por fios de cobre esmaltado. Os resultados apresentados neste trabalho se referem a fios de aço com diâmetro de $0,55 \mathrm{~mm}$ e fios de cobre com diâmetro de $1,10 \mathrm{~mm}$.

A Fig. 3 mostra a velocidade de propagação da onda em função da freqüiencia para o fio de aço deformado de $8,88 \mathrm{~mm} / \mathrm{m}$ e para o fio de cobre deformado de $2,99 \mathrm{~mm} / \mathrm{m}$.
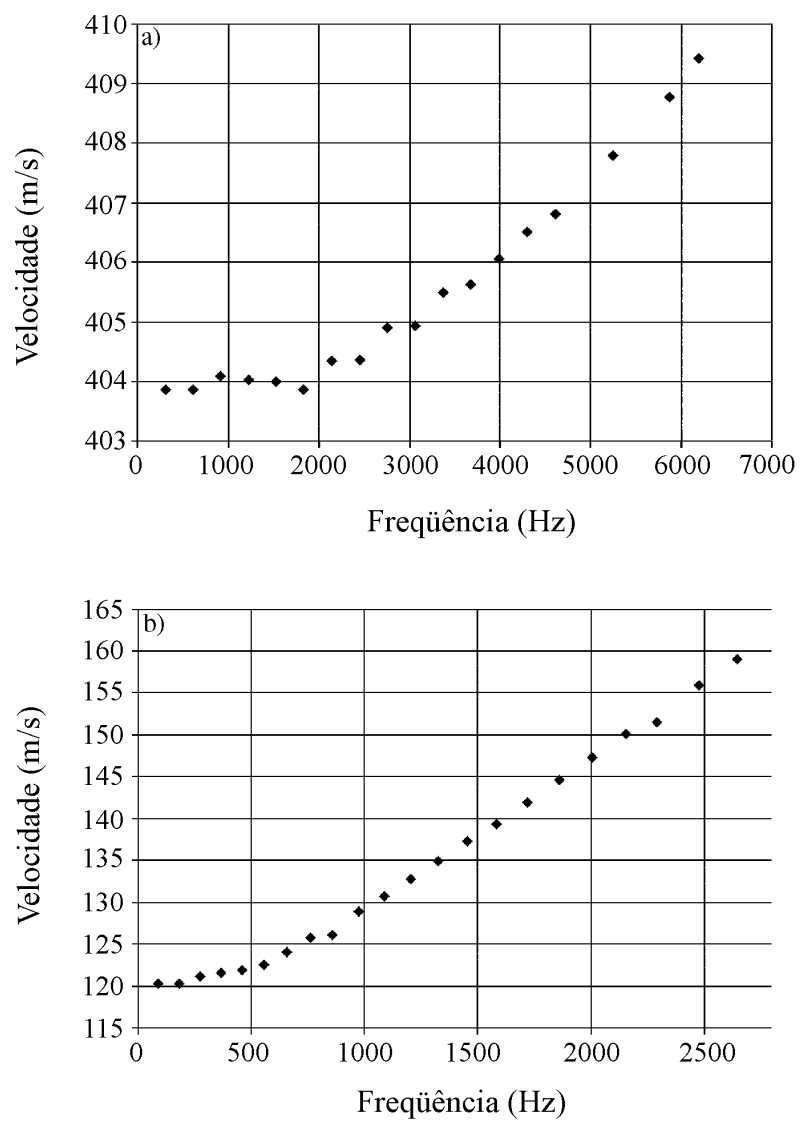

Figura 3 - Relação entre velocidade de propagação e freqüência encontrada a partir do som emitido em uma única tangida em um fio a) de aço e b) de cobre ilustram efeitos de dispersão nas ondas transversais que se propagam nos fios.

Ao analisar o espectro emitido pelos fios quando tangidos, constatou-se que as freqüências que emitem 
não correspondem a uma série harmônica. Como um fio preso em duas extremidades só pode vibrar nos modos normais tendo um nodo em cada extremidade, ficou claro que a primeira freqüência do espectro corresponde ao primeiro modo normal, a segunda freqüência ao segundo modo normal, a assim consecutivamente, o que significa que o valor do comprimento de onda e a freqüência de cada vibração estão definidos. Conclui-se, então, que a velocidade de propagação das ondas transversais não é a mesma para todas as vibrações do mesmo espectro, ou seja, há efeitos de dispersão nas ondas transversais que se propagam nos fios.

Modificações das propriedades elásticas com o tempo são ilustradas na Fig. 4, onde a tensão é medida em instantes imediatamente posteriores à sua deformação. Na Fig. 4a observa-se que no fio de aço a tensão diminui logo depois que este é esticado e tende a se estabilizar em menos de três minutos, enquanto que no fio de cobre (Fig. 4b) a estabilização ocorre cerca de uma hora depois de esticar o fio.

Durante as medidas registradas nos gráficos das Figs. 5, 6 e 7 os tempos de relaxamento não foram observados por dois motivos: i) as deformações aplicadas entre uma medida e outra são de $0,1 \mathrm{~mm} / \mathrm{m}$, portanto, muito menores que as deformações aplicadas na experiência que resultou nos dados da Fig. 4 e ii) a observação desse tempo inviabilizaria os experimentos, pois seria necessário investir centenas de horas para obter os gráficos.

A Fig. 5 apresenta as medidas da tensão em função da deformação em um fio de cobre que foi esticado girando o eixo do monocórdio de grau em grau. Por seis vezes se soltou o fio, também girando o eixo de grau em grau, até retornar dez graus, permitindo que a deformação e a tensão no fio diminuíssem. Durante estes processos de redução da deformação a declividade na curva se manteve constante e igual a $(87 \pm 3) \mathrm{kN} / \mathrm{mm}^{2}$. Este parâmetro é o módulo de Young do cobre registrado quando a deformação diminui. Ao observar novamente deformações maiores, girando o fio de cobre por aproximadamente dez graus, o fio sofre deformações elásticas, cuja declividade é, aparentemente, a mesma que a registrada quando a deformação diminui. No entanto, da análise estatística dos dados experimentais [4] obtém-se para as declividades $(79 \pm 2) \mathrm{kN} / \mathrm{mm}^{2}$. Este parâmetro é o módulo de Young registrado durante a deformação. A diferença entre os valores do módulo de Young encontrados quando a deformação aumenta e quando a deformação diminui está relacionada à histerese.
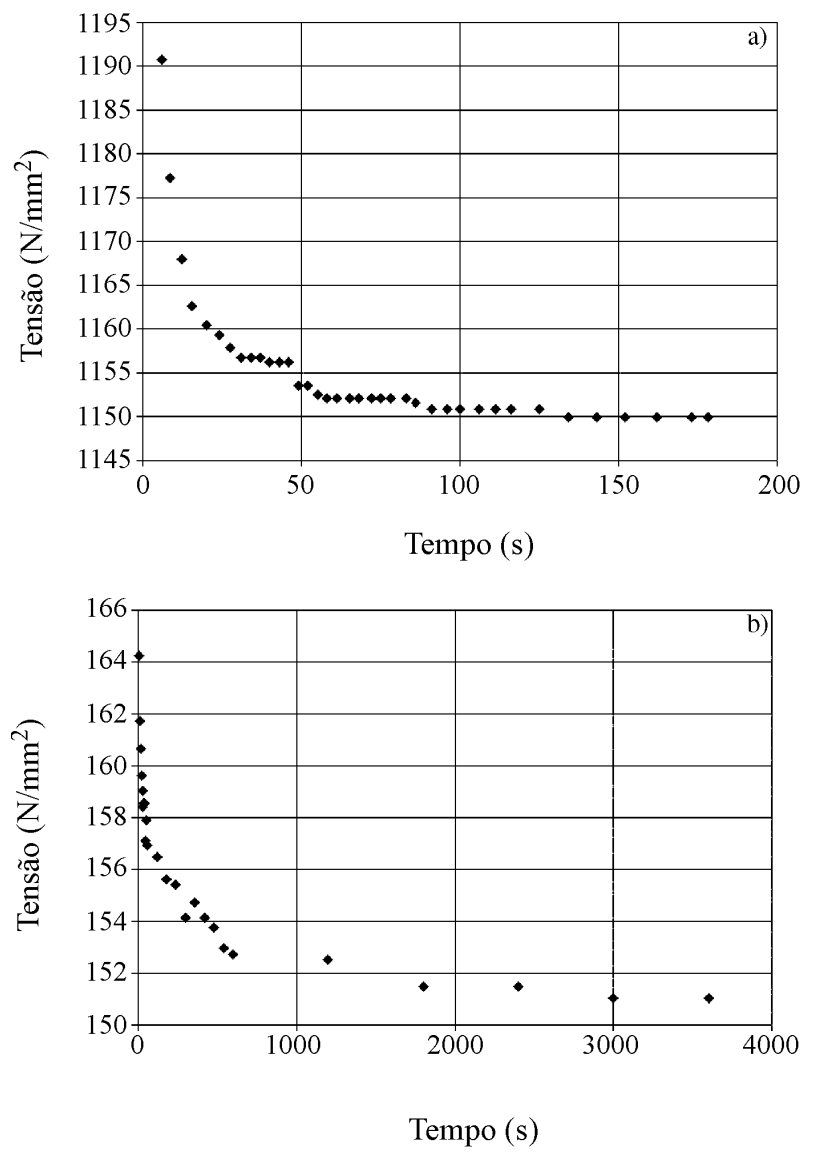

Figura 4 - Relação entre tensão e tempo para fios metálicos ilustram o relaxamento logo após sofrer deformações. a) Fio de aço deformado de $9 \mathrm{~mm} / \mathrm{m}$ e b) fio de cobre deformado de $3,2 \mathrm{~mm} / \mathrm{m}$.

Durante as deformações plásticas foi registrada uma declividade de $(1,6 \pm 0,6) \mathrm{kN} / \mathrm{mm}^{2}$, que pode ter efeitos da não observação de um tempo de relaxamento entre uma medida e outra e da não consideração da variação de diâmetro do fio durante o experimento.

Nenhuma medida no fio de cobre foi realizada com tensão menor que $60 \mathrm{~N} / \mathrm{mm}^{2}$, pois ao diminuir a tensão também diminui a intensidade da onda sonora emitida pelo fio quando este é tangido. A tensão remanescente depois de diminuir a deformação do fio por um ângulo de 10 graus foi de $(68 \pm 6) \mathrm{N} / \mathrm{mm}^{2}$. Admitindo que esta tensão se encontra na região de proporcionalidade conclui-se que o fio deve ser deformado de $(0,87 \pm 0,08) \mathrm{mm} / \mathrm{m}$ para que, ao ser tangido, emita som intenso o suficiente para sensibilizar o microfone, isso equivale a fornecer uma energia de aproximadamente $30 \mathrm{~kJ} / \mathrm{m}^{3}$ para o fio de cobre. 


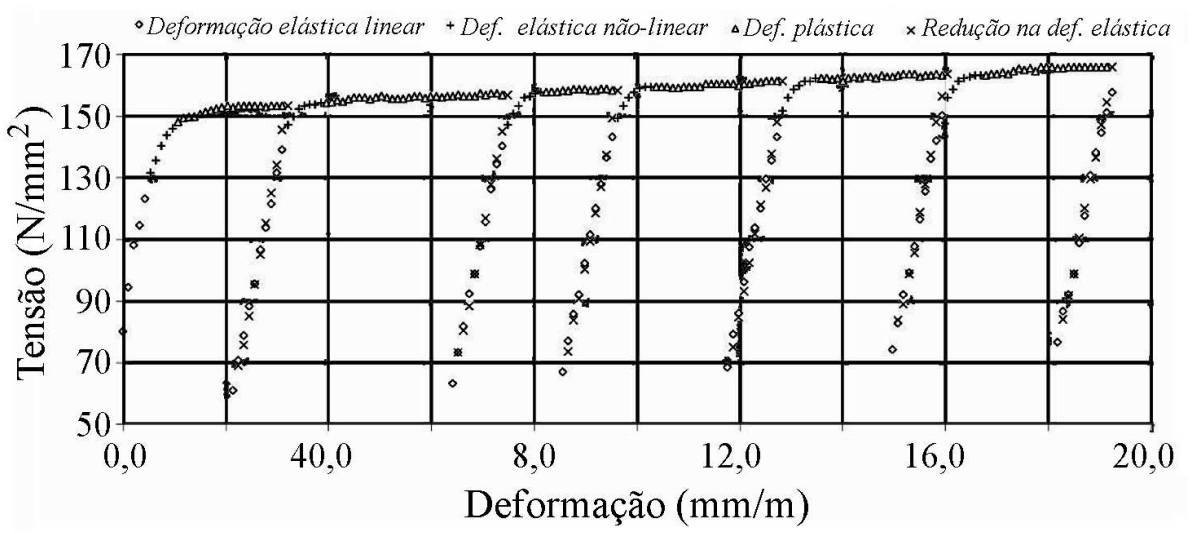

Figura 5 - Relação entre tensão e deformação medida em um fio de cobre com diâmetro de 1,1 mm.

Analisando o gráfico do ponto de vista energético, pode-se determinar a energia elástica acumulada no fio quando este atinge o limite de proporcionalidade entre $T$ e $D$ e quando passa da região elástica para a plástica. No caso do fio de cobre concluiu-se que atinge o limite de proporcionalidade com uma energia acumulada de $150 \mathrm{~kJ} / \mathrm{m}^{3}$. Esta concentração de energia elástica pode aumentar até aproximadamente $220 \mathrm{~kJ} / \mathrm{m}^{3}$, quando o fio passa para a região plástica.

Diversas vezes se diminuiu a tensão de $(92 \pm 2)$ $\mathrm{N} / \mathrm{mm}^{2}$, reduzindo a deformação em $1,07 \mathrm{~mm} / \mathrm{m}$, porém cada vez que deformação voltou a ser aumentada em $1,07 \mathrm{~mm} / \mathrm{m}$, constatou-se um incremento de tensão menor, $(83 \pm 2) \mathrm{N} / \mathrm{mm}^{2}$. Nestes procedimentos foi evidenciado que ao final de um ciclo em que a deformação é diminuída e aumentada de um mesmo valor, o incremento na tensão é significativamente menor. Esta observação é interessante, pois demonstra que a relação entre $T$ e $D$ não é simples, sendo inclusive afetada pelo tratamento mecânico ao qual o material foi submetido.

Fenômenos físicos são determinados pela energia disponível, por isso é interessante, sempre que possível, conhecer as energias envolvidas nos processos de deformação elástica e plástica do cobre. Basta, então, calcular a área sob a curva $T \times D$ para conhecer a energia por unidade de volume fornecida ao material. Nos regimes de deformação linear, em que $T=Y . D$, isto pode ser feito analítica ou numericamente. Nos regimes de deformação não-lineares, caso não se adote algum modelo para a deformação, como neste trabalho, é necessário fazer a integração numericamente para se obter a área sob a curva. Durante o regime elástico a energia necessária para produzir uma unidade de deformação depende fortemente do inter- valo de deformação considerado, pois a tensão varia rapidamente com a deformação. No regime plástico a tensão se mantém quase estável e por métodos numéricos se determinou que é necessário fornecer $(159 \pm 5) \mathrm{kJ} / \mathrm{m}^{3}$ para deformar o cobre em $1,00 \mathrm{~mm} / \mathrm{m}$; energia esta que será dissipada e a deformação será $i r$ reversivel.

Ao deformar um fio de aço adotou-se procedimento semelhante ao procedimento aplicado ao fio de cobre, mas o fio de aço não ultrapassou o limite de proporcionalidade e nem o limite de elasticidade. Depois de deformar o fio de aço, de grau em grau, até atingir uma deformação de $3,0 \mathrm{~mm} / \mathrm{m}$ soltou-se o mesmo, de grau em grau, para que sua deformação diminuísse até encontrar um ponto em que o fio não apresentasse tensão, mas o fio retornou até à sua forma original sempre mantendo tensão suficiente para ser tangido e emitir som com intensidade suficiente para gravar. $\mathrm{O}$ mesmo aconteceu quando o fio foi deformado de $6 \mathrm{~mm} / \mathrm{m}$ e de $9,0 \mathrm{~mm} / \mathrm{m}$. Curvas de histerese para dois conjuntos de dados são apresentadas na Fig. 6.

A região sob a curva que se obtém ao esticar o fio corresponde à energia por unidade de volume fornecida ao material durante a sua deformação, a região sob a curva encontrada ao soltar o fio corresponde à energia liberada pelo fio durante o relaxamento, portanto a região no interior de um ciclo de histerese corresponde à energia dissipada no processo de deformação e relaxamento. A energia dissipada durante os processos representados na Fig. 6 é de $50 \mathrm{~kJ} / \mathrm{m}^{3}$ no ciclo (a) e de $207 \mathrm{~kJ} / \mathrm{m}^{3}$ no ciclo (b). Estes valores permitem fazer a hipótese de que a energia dissipada em um ciclo de histerese é proporcional ao quadrado da amplitude da deformação. Esta hipótese está de acordo com a semelhança aparente das duas 
curvas, mas deve ser confirmada por outras medidas.
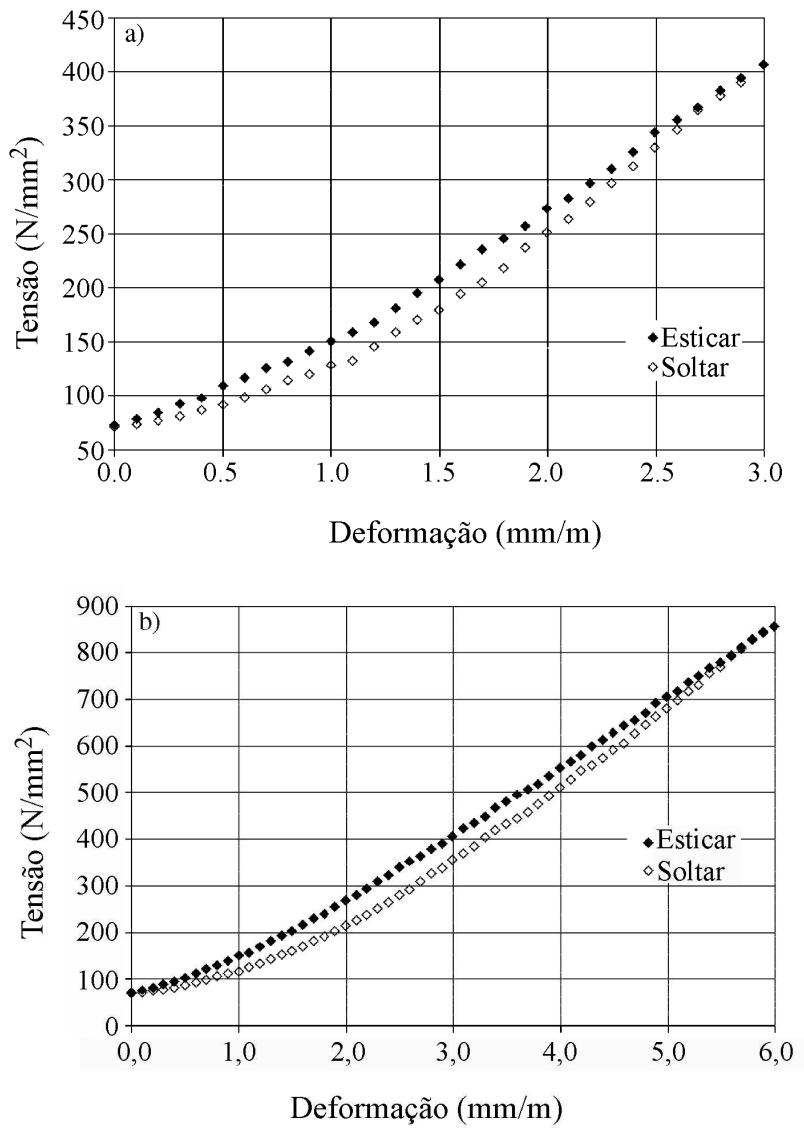

Figura 6 - Histerese em um fio de aço deformado até a) 3,0 mm/m e b) $6,0 \mathrm{~mm} / \mathrm{m}$.

Um material é considerado elástico quando não sofre deformações irreversíveis, portanto o início e o final de um ciclo de histerese devem coincidir. Isto significa que em um material que apresenta histerese é impossível que a deformação e o relaxamento sejam lineares. Deste modo, a afirmação usual de que há uma relação linear entre tensão e deformação, desde que as tensões sejam pequenas, é uma aproximação bastante boa para muitos propósitos, mas inconsistente com o modelo teórico que descreve o amortecimento de vibrações por efeitos de histerese. Este é mais um dos exemplos em que se observa que é preciso ficar atento aos limites de aplicabilidade dos modelos.

Na Fig. 7 são apresentados resultados para a tensão em função da deformação, quando os fios metálicos são deformados até o ponto de ruptura. Constata-se que a declividade da curva encontrada para o fio de aço se mantém praticamente constante até o rompimento. Não fossem os resultados apresentados anteriormente se cogitaria a hipótese do módulo de Young do aço ser constante para qualquer deformação. Para nen- hum valor de tensão a curva da Fig. 7a apresenta uma mudança evidente de comportamento na relação entre tensão e deformação, para que seja cogitada a hipótese de ter ultrapassado o limite elástico. Para deformações de até de $9 \mathrm{~mm} / \mathrm{m}$ foi confirmado experimentalmente que o fio de aço apresenta comportamento elástico, e o perfil da curva da Fig. 7a leva a crer que o comportamento do aço seja elástico até o ponto de ruptura. Isto caracteriza materiais frágeis, que se rompem assim que o limite elástico é ultrapassado.
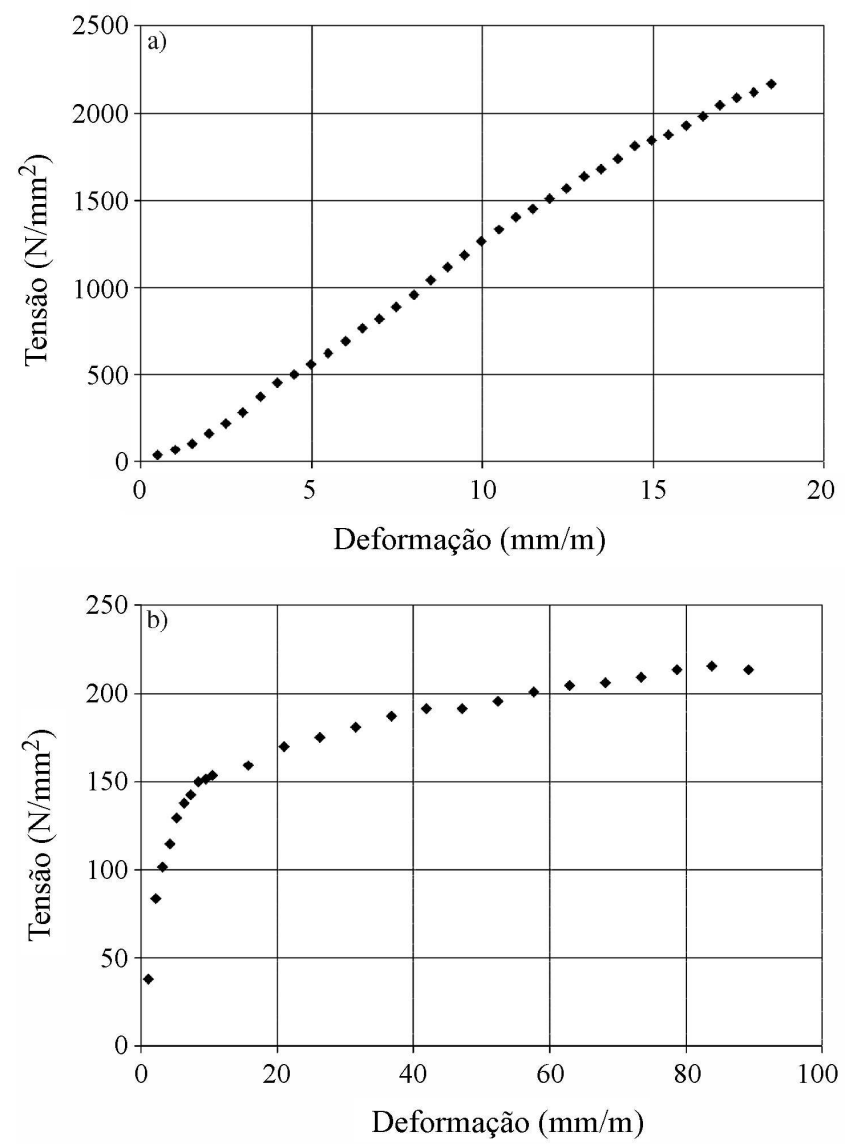

Figura 7 - Comportamento de fios a) de aço e b) de cobre (com diâmetro de $0,94 \mathrm{~mm}$ ) quando a tensão aumenta até atingir o ponto de ruptura.

O gráfico da Fig. 7b é característico dos materiais dúcteis, que suportam grandes deformações plásticas depois que o limite de elasticidade é superado. Como pode ser constatado na Fig. 5, o cobre apresenta comportamento elástico para deformações menores que $1,0 \mathrm{~mm} / \mathrm{m}$, provocadas por tensões menores do que $150 \mathrm{kN} / \mathrm{mm}^{2}$. A partir desse ponto o cobre suporta deformações irreversíveis quase 100 vezes maiores que a deformação do limite de elasticidade. Os dados apresentados na Fig. $7 \mathrm{~b}$ foram tomadas girando o eixo do monocórdio de cinco em cinco graus. Evidente- 
mente este procedimento não permitiria observar detalhes como os que podem ser observados na Fig. 4, mas permitiu analisar o comportamento dos fios quando submetidos a deformações muito grandes.

\section{Conclusão}

Neste trabalho obtivemos uma variedade de dados experimentais para fios de aço e cobre cuja análise permitiu explorar fenômenos envolvidos em fios sob tração, usualmente não considerados em disciplinas introdutórias de Física. A coleta e análise dos dados estão baseadas em conceitos básicos de física e a experiência requer tão somente um monocórdio e microcomputador, podendo, pois, ser introduzida como uma atividade experimental em disciplinas introdutórias de Física em nível universitário. Como o tempo requerido para a obtenção dos dados que nos possibilitaram estas análises ultrapassa os limites aceitáveis para atividades experimentais didáticas, disponibilizamos nossos dados.

\section{Referências}

[1] N.I. Kochkin, and M.G. Chirkévitch, Prontuário de Física Elementar (Mir, Moscou, 1986).

[2] F. Sears, M. Zeamansky, and H. Young, Física (LTC, Rio de Janeiro, 1984).

[3] R.S. Horne, Spectrogram. Disponível em: http://www.visualizationsoftware.com/gram/gramdl. html. Acesso em: 25 agosto 2004.

[4] L.A. Mützenberg, Estudo da Resistência de Fios de Aço e Cobre: Tabelas de Resultados Experimentais. Disponível em: http://www.if.ufrgs.br/cref/ntef/gram/. Acesso em: 12 outubro 2004. 